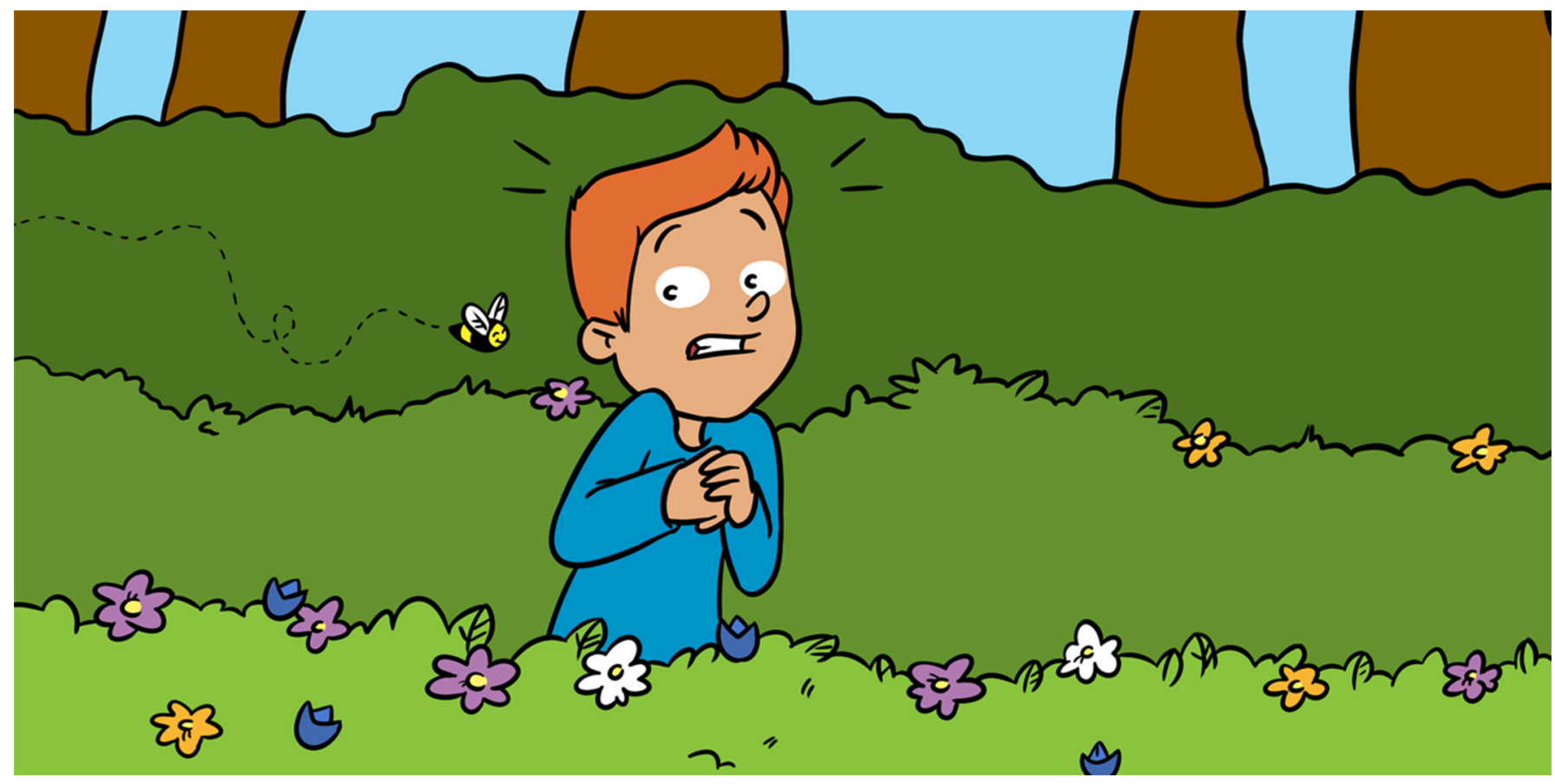

\title{
LOOK OUT! HOW TEAMS OF BRAIN CELLS HELP KEEP US SAFE FROM HARM
}

\section{Lindsay R. Halladay *}

Department of Psychology, Santa Clara University, Santa Clara, CA, United States

YOUNG REVIEWERS:

EXPLORA

SCIENCE

CENTER

AND

CHILDREN'S

MUSEUM

AGE: 8-14
As we navigate the world around us, sometimes we are faced with danger. Our brains help keep us safe from harm, but we do not fully understand how they do this. How do our brains decide to make us freeze in place when we hear bees buzzing, so that they ignore us and buzz on by? And when those bees are angry, how do our brains decide that running away is a better option than freezing? Answers to these questions will help us understand how our brains make decisions when we are afraid, and will also allow us to determine what may be going wrong in the brains of people who have too much fear-like people with anxiety. Our research shows that an area of the brain called the prefrontal cortex contains teams of brain cells that help us to freeze or to run away, depending on how much danger we are in.

The brain is incredibly complex. It does everything from making your heart beat to giving you your unique personality. But when brains are not working optimally, people can suffer from things like anxiety disorders. So, scientists are busy trying to figure out how our complex 
brains function, so that we can help people with disorders related to the brain.

\section{THE BRAIN HELPS KEEP US SAFE}

Imagine you are walking in a park full of brightly colored flowers and some of their greatest admirers-honey bees. Suddenly, you hear the buzzing of a bee very near your ear. Without even thinking about it, your muscles tense up, and you stop dead in your tracks. You find yourself frozen, hoping the bee ignores you and buzzes on by.

What just happened?

Well, one of your brain's most important jobs is keeping you safe. Somewhere in your past, you learned two things: First, bees can sting! And second, bees buzz. So, when your ears perked up at the sound of bees buzzing, alarm bells went off in your brain. Your brain responded by telling your muscles to freeze so that the bee would hopefully just buzz off. And you did not even have to think about it... Pretty cool!

Now imagine something just a little different. You are taking an afternoon stroll through the very same park, but earlier that morning an angry bee stung you in the arm-and it hurt! So now when you hear bees buzzing in the park, will your brain, whose job is to protect you, simply tell your body to freeze in place? Heck no! The recent, painful bee sting is fresh in your mind. So, instead of freezing in place, it is more likely that your brain will tell your body to hightail it out of the park as fast as your legs can take you! (Figure 1).

Freezing and running away are normal reactions that your brain may choose in order to keep you safe from harm. During both of your trips to the park, the bee's buzzes alert your brain that danger may be nearby. Your body reacts differently depending on how much danger there is or, in this example, whether you were stung earlier that morning. This would be similar to the way you might react differently to a bully, depending on your recent encounters with him, or your response during an earthquake, depending on whether there had been another quake just hours before. The question is, how does your brain know which response is best to keep you safe?

NEUROSCIENTIST

A scientist who studies the brain and nervous system.

\section{WHY DO WE CARE WHAT THE BRAIN IS DOING?}

Scientists who study the brain, called neuroscientists, want to understand how the brain helps us react when we are afraid. One reason it is important to understand this is because some people naturally over react and have too much fear. Too much fear is bad because it can keep us from doing fun or important things. For example, if someone has too much fear of bees buzzing, that person 
Figure 1

Our response to scary situations is influenced by recent events. For example, if you hear bees buzzing nearby, your brain may tell your muscles to freeze, in hopes that the bees will just buzz off (top). But if you have recently been stung by a bee, your brain's response is likely to be more urgent-it may tell your body to get a move on to help keep you away from danger (bottom).

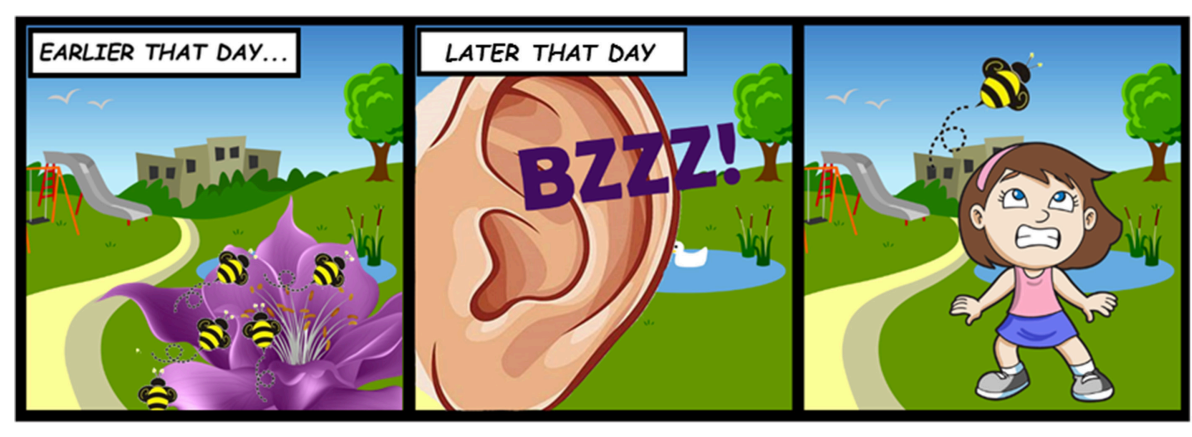

\section{Compared to:}

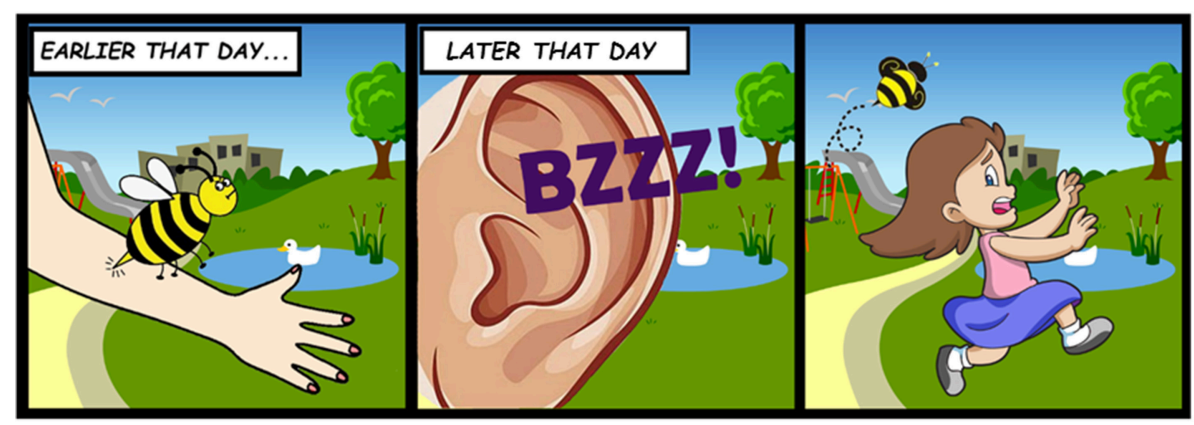

Figure 1

may stop going to the park entirely! But adjusting the fear response of the brain is tricky, because we still want people to have some fear, so that they can recognize danger and not get hurt. So, by understanding which parts of the brain tell us to freeze and which parts tell us to run, neuroscientists can start to figure out how to help all people react appropriately in scary situations.

\section{LAB ANIMALS HELP US UNDERSTAND HUMAN BEHAVIOR}

Many neuroscientists like me need the help of some furry friends-in this case the commonly used lab rat-to learn about the brain. Rats have surprisingly similar brains to ours. Rats also behave much like we do in scary situations: when rats are afraid, sometimes they freeze and sometimes they run away. So, using rats in the lab can help us study how the brain reacts during scary situations, like our example with the bees in Figure 1.

Now, rats are not afraid of bees' buzzes like we are (and it is hard to make a bee sting on command!) Instead of a buzzing sound, we taught our rats to be afraid of a crackling white noise sound (Figure 2). White noise is usually not scary, but if a rat hears white noise just before something bad happens, like a shock to its paw, the rat quickly becomes afraid of the white noise, since it has become a signal for danger. In other words, the rat knows his paw might get zapped (just 
Figure 2

We use lab rats to study how our brains help keep us safe from danger. (A) Rats were trained to know that a specific white noise sound meant they might receive a zap to their paw. (B) Just like humans, rats change the way they respond in scary situations depending on how much danger they perceive. (C) When trained rats have not recently been zapped, the white noise makes their body slow down (freeze) compared to how quickly they normally scurry around ("baseline"). But after recently being zapped, rats run away in response to the white noise instead of freezing.

\section{NEURON}

A specialized cell in the nervous system that transmits information to other cells.
A
ON TRAINING DAYS:

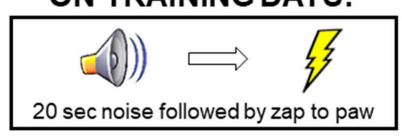

ON TEST DAYS:

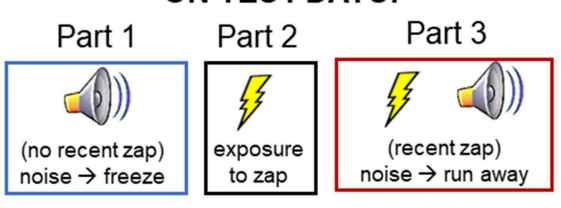

C

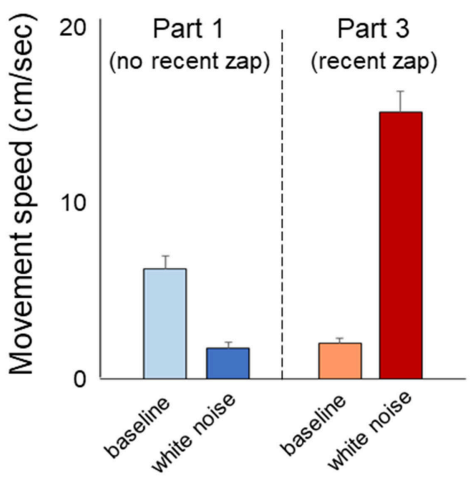

B

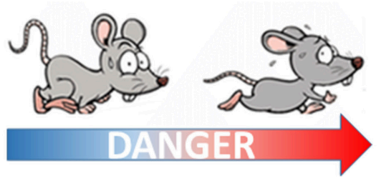

Figure 2

like the bee sting) after he hears the white noise (just like the buzz). How do you think lab rats react to the scary white noise?

Well it turns out, just like us, rats react to danger by freezing or running away! And, just like us, rats sometimes freeze and sometimes run away depending on the situation. Rats usually freeze when they hear the scary white noise. But we discovered that, if a rat's paw has already been zapped earlier in the day, instead of freezing, he will run away (Figures 2B,C) [1]. So, in the same situation, rats will either freeze or run away depending on how much danger they perceive. This is exactly like a recent bee sting that makes you run away instead of freeze when you hear buzzing! So, the situation of the rats responding to white noise is perfect for us to study how the brain tells the body to act when danger is near, because we can use it to compare the activity in the brain during freezing (low danger) to the activity in the brain during running away (high danger).

\section{STUDYING THE BRAIN}

I told you that neuroscientists study the brain. But how exactly do they do that? First, I should tell you that, in the brain, special cells called neurons work together to help us think and act (Figure 3A). There are many kinds of neurons in the brain that have many different jobs. One kind of neuron's job is to act like an alarm-to share information about noises we have learned to be afraid of, such as bees' buzzing. These neurons can be found in a part of the brain called the amygdala. Neuroscientists understand quite a bit about how these "alarm bell" neurons receive information from our sense organs, like our ears and eyes. But scientists do not know for sure yet how the alarm 
Figure 3

(A) We studied an area of the brain called the prefrontal cortex (PFC), which helps us make decisions, to see if brain cells (neurons) there help us decide to freeze or run away during danger. (B) Neurons communicate using electrical signals called action potentials that can be recorded as rats scurry around. This technique is called in vivo electrophysiology. We recorded action potentials in trained rats as they encountered the white noise to help us understand how neurons communicate with each other during danger. Our brains are very similar to rats brains, so we can use this information to understand how our own brains help keep us safe.

ACTION POTENTIAL

The electrical signal used by neurons to transmit information.

\section{IN VIVO}

ELECTROPHYSIOLOGY

A method to measure activity of neurons in an animal during different behaviors.

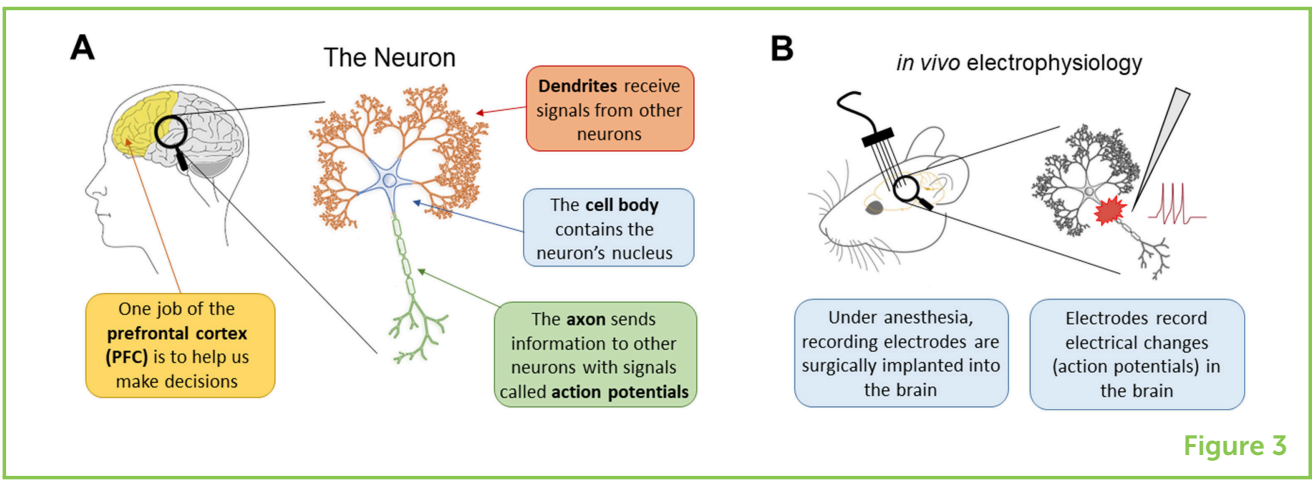

bell neurons pass on information to other neurons that control our body movements. So, my lab designed experiments to help figure that out.

Neurons communicate with each other using electrical signals called action potentials. During an action potential, an electrical impulse is sent from the neuron's cell body down its axon, which causes chemicals called neurotransmitters to be released. Those neurotransmitters contact the next neuron's dendrites to deliver the message from the first neuron. You can think of action potentials as a neuron shouting out a message to other nearby neurons. We also refer to action potentials as "spikes" or "firing."

In my lab, we use special equipment to listen to action potentials as a rat scurries around, kind of like eavesdropping in on a phone conversation. This technique is called in vivo electrophysiology - "in vivo" means in a living thing, "electro" refers to electric current, and "physiology" refers to studying how organisms function. To conduct in vivo electrophysiology experiments, we carefully implant recording electrodes in the brain while a rat is under anesthesia (Figure 3B). Once the rat has fully recovered from surgery and is scurrying around normally, those electrodes sense electrical changes in the brain and, with the help of computers, we can record action potentials taking place during almost any activity our rat is doing. What is really cool is that, just like people, neurons have different "voices," so we can keep track of what many different neurons are saying, all at the same time. This is super exciting because, at the very same time that we can hear neurons communicating, we can also see what a rat is doing and start to figure out which neurons are shouting "Freeze!" and which are shouting "Run away!" (Figure 4).

If a neuron becomes noisy every time a rat hears the scary white noise, we may assume that neuron is acting like an alarm bell, alerting the rest of the brain to potential danger. But, if another neuron is quiet when a rat freezes and becomes noisy only when he runs away, we might say that neuron is in charge of sending a "Run away!" message. Remember, identifying which neurons tell you to be afraid and which ones tell your body to freeze or to run away may help create treatments for 
Figure 4

We recorded neurons communicating in the PFC of our trained rats as they encountered the white noise, both before and after being recently zapped. We discovered that some neurons were very active only when rats froze in response to the white noise, but not when they ran away. We also found other neurons that did the opposite-they were very active when the rats responded to the white noise by running away, but not when they froze. This means that there could be two different teams of neurons in the PFC that help us either freeze or run away when faced with danger, depending on how scary the situation is.

\section{PREFRONTAL}

\section{CORTEX (PFC)}

Region in the frontal lobe of the brain that helps us

make decisions.

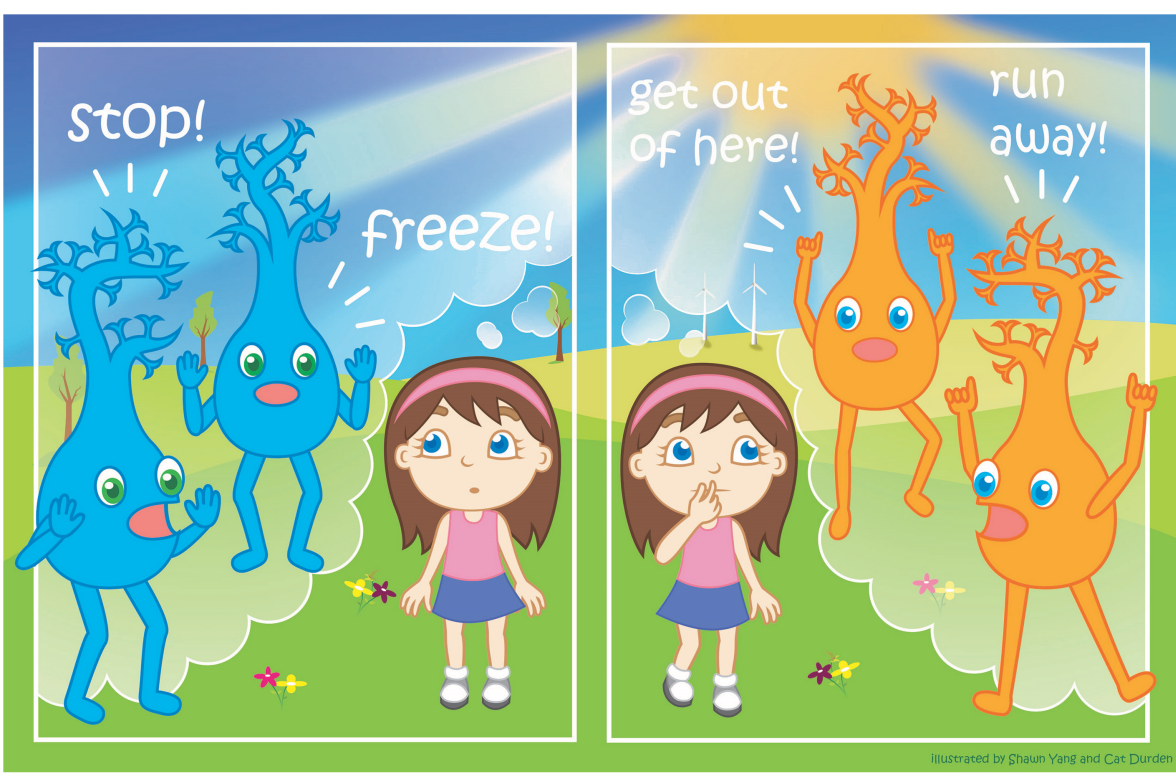

Figure 4

people with too much fear. For example, someone who is too afraid (someone who may run away from the park even if he was never stung by a bee) might benefit from a treatment that quiets down his "Run Away" neurons so that his "Freeze" neurons can be heard.

\section{NOW, ON TO OUR DISCOVERIES!}

Past experiments from other labs have discovered that the amygdala (the brain area with the alarm bell neurons we talked about before) is important for helping us feel emotions like fear. But we wanted to know how our brains help us switch between different responses to scary situations, so we wondered what neurons were doing in the decision-making parts of the brain during fear. So, when our rats either froze or ran away during the scary white noise, we listened to many dozens of neurons in the prefrontal cortex (PFC for short), an area that helps both rats and humans make decisions. And there we found neurons doing something special! We found one group of neurons that became very talkative when rats froze in response to the white noise but were very quiet when rats ran away. An entirely different group of neurons became very talkative only when rats ran away from the white noise but were quiet when rats froze. Most importantly, neurons in the PFC that were communicating during freezing or running away only became noisy during one response (freezing OR running away) and not the other [2].

So, what does this all mean?? It seems that PFC neurons are not acting like alarm bells after all, because in that case they would be noisy during both freezing and running away. But rather, different teams of neurons in the PFC send very specific orders to either freeze or run 
away. So, when your brain senses that you are in danger when you hear buzzing in the park, a team of neurons cheers "Freeze!" and your body instantly stays still so the bee does not notice you. But if you have already been stung in the park, a different team of neurons cheers "Run away!" to help you hightail it out of the park to avoid those angry bees $[2,3]$.

Now, we know neurons in the PFC communicate with other neurons all over the brain. Many other neuroscientists have found evidence that other parts of the brain like the amygdala (where alarm bell neurons can be found) are important for emotions like fear. And neuroscientists also know that the PFC can regulate emotions by communicating with the amygdala. However, our findings showed, for the first time, that teams of neurons in the PFC promote different types of behaviors, not just fear in general.

This is fantastic news. Remember, neuroscientists know a lot about how your ears send information about bees' buzzes to your brain to alert you of danger. But what is not known is exactly which neurons help us decide what to do. Our experiment showed that in the PFC, teams of neurons have very specific jobs-one team tells us to freeze during low levels of danger, and an entirely different team tells us to run away during high levels of danger [2]. This is great news for people who have too much fear, because one day medications affecting the PFC might be able to quiet down the "Run Away" neurons while allowing the "Freeze" neurons to communicate normally-so people could have just the right amount of fear needed to keep them safe!

Of course there is still a lot left to learn. For example, we cannot just turn off our "Run Away" neurons entirely, because sometimes we need to be able to run away from dangers like angry bees. We also do not know yet which neurons tell the "Freeze" and "Run Away" teams of neurons how long ago you were last stung in the park. One thing is for sure though-since the PFC contains teams of neurons with special jobs to carry out during danger, the PFC might be the brain area that is not working quite right in people with anxiety. So, we are one step closer to helping create better treatments for the many, many people who need them.

\section{ACKNOWLEDGMENTS}

We thank Shawn Yang and Cat Durden for their artistic contribution of Figure 4. Additional thanks to Dr. H. Tad Blair, who conceptualized the behavioral model and original research this article is based upon.

\section{ORIGINAL SOURCE ARTICLE}

Halladay, L. R., and Blair, H. T. 2015. Distinct ensembles of medial prefrontal cortex neurons are activated by threatening stimuli that elicit 
excitation vs. inhibition of movement. J. Neurophysiol. 114:793-807. doi: 10.1152/jn.00656.2014

\section{REFERENCES}

1. Tarpley, J. W., Shlifer, I. G., Halladay, L. R., and Blair, H. T. 2010. Conditioned turning behavior: a pavlovian fear response expressed during the post-encounter period following aversive stimulation. Neuroscience. 169:1689-704. doi: 10.1016/j.neuroscience.2010.06.046

2. Halladay, L. R., and Blair, H. T. 2015. Distinct ensembles of medial prefrontal cortex neurons are activated by threatening stimuli that elicit excitation vs. inhibition of movement. J. Neurophysiol. 114:793-807. doi: 10.1152/jn.00656.2014

3. Halladay, L. R., and Blair, H. T. 2017. Prefrontal infralimbic cortex mediates competition between excitation and inhibition of body movements during pavlovian fear conditioning. J. Neurosci. Res. 95:853-62. doi: 10.1002/jnr.23736

SUBMITTED: 26 November 2018; ACCEPTED: 23 April 2019;

PUBLISHED ONLINE: 08 May 2019.

EDITED BY: Kathleen Y. Haaland, University of New Mexico, United States

CITATION: Halladay LR (2019) Look Out! How Teams of Brain Cells Help Keep Us Safe From Harm. Front. Young Minds 7:63. doi: 10.3389/frym.2019.00063

CONFLICT OF INTEREST STATEMENT: The author declares that the research was conducted in the absence of any commercial or financial relationships that could be construed as a potential conflict of interest.

COPYRIGHT () 2019 Halladay. This is an open-access article distributed under the terms of the Creative Commons Attribution License (CC BY). The use, distribution or reproduction in other forums is permitted, provided the original author(s) and the copyright owner(s) are credited and that the original publication in this journal is cited, in accordance with accepted academic practice. No use, distribution or reproduction is permitted which does not comply with these terms.

\section{YOUNG REVIEWERS}

\section{EXPLORA SCIENCE CENTER AND CHILDREN'S MUSEUM, AGE: 8-14}

The Explora Young Minds reviewers are a group of science enthusiasts working with museum educators and mentors from the University of New Mexico. We enjoy learning about the brain through the articles. We also enjoy asking questions and making suggestions to help the scientists make their work more understandable for everyone! We were helped by our Science Mentor Jennifer Walter. She just received her Ph.D. in pediatric neuropsychology. She enjoys working with kids, playing with her dog, and trying to cook new recipes. 


\section{AUTHOR}

\section{LINDSAY R. HALLADAY}

I am an Assistant Professor in Psychology and Neuroscience at Santa Clara University in California. I research how neurons and circuits in the brain produce behavior, and am especially interested in how dysfunction in the brain can lead to abnormal behavior. *halladay@scu.edu 